\title{
Economic Efficiency of Input Use in Peach Cultivation in North Western Himalayas
}

\author{
Pardeep Singh", M.K. Vaidya and Amit Gularia \\ Department of Social Sciences, Dr. Yashwant Singh Parmar University of Horticulture and Forestry Nauni, Solan-173230, Himachal \\ Pradesh, India \\ *Corresponding author: amitguleria1201@gmail.com
}

\begin{abstract}
Peach is the most important stone fruit in temperate and sub-tropical areas. Among the stone fruits, peach crop accounts for 49.54 per cent in area and 60.82 per cent production in Himachal Pradesh. A sample of 60 farmers cultivating peach was selected using multistage simple random sampling. Results of the study revealed that literacy rate in the study area were worked out to 82.57 per cent with literacy index of 2.23 indicating low quality of education. Average operational area was found 1.26 ha, out of which orchard area was 0.83 ha and peach plantation accounts for 52.38 per cent. The cultivation of peach component was also seem to be quite important; with its contribution to total household income was 45.54 per cent. It has been observed that fertilizer, FYM and Labour were significantly affecting the production but plant protection chemical was not found significant. It has been observed that Fertilizer, FYM, Plant Protection Chemicals and Labour were found to be significantly under-utilized resources and increase the use of these inputs will increase production. The findings of the study strongly recommend the optimum use of the resources in order to attain desired growth in peach cultivation and ultimately the productivity.
\end{abstract}

Keywords: Cropping pattern, resource use efficiency, peach, household income

India is the second largest producer of fruits in the world. It has made good progress in horticulture scenario with a total fruit production of 89018 thousands MT from an area of 6188 thousands ha (Anonymous 2016a). Horticulture sector has a significant impact on the growth of the country's economy and is expected that in future also it can make significant contribution towards accelerating the agricultural growth. Himachal Pradesh is known as the fruit bowl of the country. The state is having the advantage of varied climate ranging from subtropical to dry temperate. Horticulture sector in the states has made remarkable contributions in the up liftment of the socio-economic conditions of the farming community. The niche advantages for fruits have in the past been exploited by the growers, wherever natural conditions, socioeconomic and institutional environments were favourable. The increase in area and productivity of fruit crops in the state has pushed up the total production manifold during last few decades and consequently the marketable surplus. The total fruit production in the state was 928.83 thousand Mt from area of 226.80 thousand ha (Anonymous $2016 \mathrm{~b}$ ). The stone fruits are the second major fruit crop in the state. The peach (Prunus persica) is one of the major stone fruit crop and it accounts for 5.08 thousand ha area with production of 8.05 thousand Mt (Anonymous 2016b). The land is a limiting factor, the net sown area being only about one tenth of the total geographical area of the state. Under such circumstances a major section of the farming community cannot hope to raise its standard of living by exclusive dependence on agriculture and thus the best alternative for the state is to utilize its natural gifts for other high payoff vocation and fruit farming is one of such enterprise best suited to its terrain and climate.

The peach (Prunus persica Batsch) is an important stone fruit crop. It belongs to family Rosaceae 
and is cultivated for table purposes as well as for processing. It is highly valued for its taste and attractive colour. It is commercially grown in the temperate zone of the world extending from $10^{\circ}$ North and $49^{\circ}$ South latitude where strong light, clear sky, long seasons and warm temperature prevail mainly in low and mid hills with altitudinal range of 1000-2000m above mean sea level (Ghosh, 2001). In Himachal Pradesh, Peach is being grown in almost all the districts except in dry and cold climates of Kinnaur, Lahul Spiti and Chamba district. (Awasthi et al. 1999). The peach orchards, however, are predominant in Sirmaur District, where commercial plantation of peach exists. The main cultivars of peach being grown in mid- hills of H.P. are July Elberta, Red Haven, Early white Giant and World's Earliest etc. Out of these July Elberta accounts for 75 per cent of the total production of peach in the state (Nijjar et al. 1979). The low chill peaches developed in the past 20 years are promising for commercial production. Through judicious introduction a variation may be added to the fruit bowl of subtropical fruits and large unexploited areas in different parts of India can be subjected for cultivation of such peaches. This study has been carried out in order to determine resource utilization of peach farms with following specific objectives: (i) Farm specific characteristics of peach growers of north western Himalayas and (ii) Resource use efficiency of peach in the study area.

\section{Data Base and Methodology}

The present study was undertaken during 2017 in the Sirmaur district of Himachal Pradesh being a major hub of peach crop in India and situated between $30.8500^{\circ}$ North latitude and $77.2994^{\circ}$ East longitude as shown in Fig 1. A Multistage simple random sampling technique was used for the selection of the respondents. At first stage, Rajgarh block out of 6 blocks in Sirmaur district was selected on the basis of maximum area under peach plantation. At second stage, a list of panchayats growing peach in Rajgarh block was prepared which comes to 15 panchayats and out of these, 6 panchayats were selected randomly. It forms a belt of peach farmers including Bhanat, Bhuria, Neri Kotli, Thaina Basotri, Serjagas and Shallana panchyats. At third stage complete list of villages of selected six panchayats was prepared and 2 villages were selected randomly from each panchayat to constitute a total of 12 villages. At fourth stage, list of farmers growing peach was prepared and a sample of 5 respondents from each village was selected randomly, thus, 60 peach growers were ultimately selected for collecting data as presented in Fig 2.

Multiple regression analysis was carried out to know the factors influencing the peach production and for evaluating the economic efficiency of resources. Some of the non-strategic collinear variables were dropped from the analysis to improve the precision of regression parameter. The variables considered for explaining the level of production at the farmers end in regression equations. The Cobb-Douglas production function was employed in this study as it gave the best fit compared to the linear, exponential and semi-log functional forms. The linear stochastic form of the specified Cobb Douglas function is given as;

$$
Y=a X_{1}^{b_{1}} X_{2}^{b_{2}} X_{3}^{b_{3}} X_{4}^{b_{4}} X_{4}^{b_{4}} u_{i}
$$

\section{Log-log equations}

$$
\begin{aligned}
& \begin{aligned}
\log Y= & \log a+b_{1} \log X_{1}+b_{2} \log X_{2}+b_{3} \log X_{3}+b_{4} \\
& \log X_{4}+\log u_{i}
\end{aligned} \\
& \mathrm{Y}=\text { Gross returns per hundred plants (quintals) } \\
& \mathrm{X}_{1}=\text { Expenditure on fertilizers (quintals) } \\
& \mathrm{X}_{2}=\text { Expenditure on farm yard manure (quintals) } \\
& \mathrm{X}_{3}=\text { Expenditure on plant protection measures } \\
& (\mathrm{Kg}) \\
& \mathrm{X}_{4}=\text { Human labour expenditure (mandays) } \\
& \mathrm{u}_{\mathrm{i}}=\text { Stochastic error term } \\
& \mathrm{a}=\text { Intercept and } \mathrm{b}_{1} \text { to } \mathrm{b}_{4} \text { are the elasticity } \\
& \text { coefficients. }
\end{aligned}
$$

\section{Resource-use Efficiency}

The estimated coefficients of significant independent variables were used to compute the marginal value products (MVP) and the resources-use efficiency (r) was worked out (Rahman and Lawal, 2003):

$$
r=\frac{M V P}{M I C}
$$

where, $M V P_{i}=\beta_{i} \frac{\bar{Y}}{\bar{X}_{i}} \times P_{y}$

Here,

$$
M V P_{i}=\text { Marginal value product of the } \mathrm{i}^{\text {th }} \text { input, }
$$


$\mathrm{Y}=$ Geometric mean of the value of output,

$X_{i}=$ Geometric mean of the $\mathrm{i}^{\text {th }}$ input,

$\beta_{i}=$ Estimated coefficient (or) elasticity of the $i^{\text {th }}$

input, and

$P_{y}=$ Price of output.

The relative percentage change in MVP of each resource was required to obtain optimal resource allocation estimated:

$$
D=\left(1-\frac{M I C}{M V P}\right) \times 100
$$

where, $\mathrm{D}$ is the absolute value of percentage change in MVP of each resource (Mijindadi, 1980).

The decision rule for the efficiency analysis is if: $\mathrm{r}=1$; resource is been used efficiently

$r>1$; resource is under-utilization and increased utilization will increase output.

$\mathrm{r}<1$; resource is over utilized and reduction in its usage would lead to maximization of profit.

\section{Significance of efficiency ratio}

$\mathrm{H}_{0}=$ resources are efficiently used

$\mathrm{H}_{1}=$ resources are inefficiently used

$t$ statistic was used to compare with significant $t$ table value at 0.05 level of probability.

\section{RESULTS AND DISCUSSION}

\section{Farm specific characteristics of peach growers in north western Himalayan}

The size and structure of the family, work force and literacy status among the sampled farmers are the important factors which influencing the production. These factors determine the socio-economic wellbeing and standard of living of the family that plays a vital role in farm business and marketing activities. The socio-economic characteristics of sampled household in the study area have been presented in Table 1.

The perusal of table shows that total number of families has been found to be 60 , out of which 36.67 per cent were joint families and 63.33 per cent nuclear families in the sampled households. The average size of family was 5.83 members per family out of which 52.66 per cent member per family were male and 47.34 per cent member per family female in the sampled households and number of females per thousand of males were found to be 901 . The literacy rate and literacy index of the study area was 82.57 per cent and 2.23, respectively. This highlights the fact that literacy rate in the study areas was quite higher, but the quality of education was poor as indicated by low literacy index.

Table 1: Farm specific characteristics of sampled household

\begin{tabular}{lc}
\hline Particulars & Value \\
\hline Number of the Family & 60.00 \\
Joint Family (\%) & $22(36.67)$ \\
Nuclear Family (\%) & $38(63.33)$ \\
Average size of Family & 5.83 \\
Male & $3.07(52.66)$ \\
Female & $2.76(47.34)$ \\
Sex ratio & 901 \\
Literacy rate (\%) & 82.57 \\
Literacy index & 2.23 \\
Service (\%) & 9.75 \\
Business (\%) & 6.82 \\
Agriculture (\%) & 83.43 \\
Average No. of workers & $4.61(79.12)$ \\
Average No. of dependents (<14yrs \& $>65$ & \\
yrs) & $1.22(20.88)$ \\
Dependency Ratio w.r.t. family size & $1: 4.76$ \\
Average area under peach (ha) & $0.66(52.38)$ \\
Irrigated land & $0.98(77.78)$ \\
Total cultivated area (ha) & $1.26(67.02)$ \\
Total land holding (ha) & 1.88 \\
Cropping intensity (\%) & 122.87 \\
Animal standard unit & 2.13 \\
\hline
\end{tabular}

Figures in parentheses are percentage

The average size of the family was 5.83 member per family out of which 79.12 per cent were active workers and also 20.88 per cent were dependents in the family. It is noted that agriculture has the main occupation as 83.43 per cent of work force practice farming. On an average 9.75 per cent workers population were engaged in public/private services as secondary occupation and 6.82 per cent population engaged in business. Dependency ratio with respect to family size was 1:4.76. Average size of land holding per sampled respondents was found to be 1.88 hectare, out of which 67.02 per cent hectare was cultivated area. The cropping 
intensity of the study area was 122.87 per cent. Average animal standard unit per household was found to be 2.13. Area under peach has been found to be 52.38 per cent out of total cultivated land. The cropping intensity and average animal standard unit per household has been found to be 122.87 per cent and 2.13 respectively.

\section{Resource use efficiency of peach in north western Himalayan}

Resource use efficiency has been used to explain the contribution of individual factor/input in the total output/yield, production function analysis is helpful to evaluate the efficiency of various inputs or resources used by the farmers. The elasticity coefficient of inputs/factor used in the production of peach has been worked out by fitting Cobb-Douglas production function.

The input-output data for peach were converted into their respective per hundred plant equivalents. The estimates of the fitted production function were used to study the effect of different variables on output, production elasticity, resource use efficiency and return to scale. The estimated regression coefficient with their standard error and the value of adjusted coefficient of multiple determinations are given and discussed below.

The results of the production function analysis of peach have been given in Table 2 . In the analysis of this regression equation, four explanatory variables are included, based on the theoretical considerations. Planting material and Irrigation are excluded from the analysis, as these variables are common for all the farmers in the present study.

Table 2: Estimated Production Functions of peach of north western Himalayan

\begin{tabular}{ccc}
\hline Variables & Coefficient & Std. Error \\
\hline Intercept & 0.42 & 0.28 \\
Fertilizer & $0.53^{* *}$ & 0.12 \\
FYM & $0.11^{*}$ & 0.07 \\
Plant protection & 0.14 & 0.15 \\
Labour & $0.40^{* *}$ & 0.15 \\
$\sum \mathrm{bi}$ & $1.04^{* *}$ & F-statistic $=136.66$ \\
$\mathrm{R}^{2}$ & $0.91^{* *}$ & Adjusted $\mathrm{R}^{2}=0.90$ \\
\hline
\end{tabular}

${ }^{* *} p<0.01 ;{ }^{*} p<0.10$.

Analysis of peach farms shows that the value of
$\left(R^{2}\right)$ is 0.90 and the same is found to be significant at 1 per cent level. This indicated that 90 per cent of variation in the total output of peach was explained by the independent variables, included in the function. The sum of elasticity coefficients $\left(\sum \mathrm{bi}=\right.$ 1.06) is greater than unity, which shows increasing returns to scale on average farm peach production and operated under sub-optimal level, inputs has increased to achieve the profit maximization level.

Amongst the variable included, it has been found that fertilizer has highly significant at 1 per cent level and also similar result has been showed by Chand et al. (2017). The result shows that one per cent change in fertilizer leads to change in the yield level by 0.53 per cent.

It has been observed that partial regression coefficient of FYM was found to be 0.11 which was positive and significant at 10 per cent level. It inferred that if one per cent increases in use of FYM over its geometric mean, it would lead to increase peach production by 0.11 per cent. The regression co-efficient of labour cost per 100 plants for a peach growers has been found to be 0.40 which has been significant at 1 per cent level and similar results were presented by Chapke et al. in 2011. It also indicates that considering all other factors constant, one percent increase of labour cost would increase gross return by 0.40 per cent.

The plant protection chemicals not found to be statistically significant but it is positive which means positively affect the production. If there is one per cent change in plant protection chemicals, the peach production will increase by 0.11 per cent. This analysis shows that for getting the maximum output, the proper combination of these variables should be used to increase the efficiency of the resources under peach cultivation.

\section{Efficiency of Resource use in peach cultivation}

Resource use efficiency in agriculture is defined to include the concepts of technical efficiency, allocative efficiency and environmental efficiency. Public investment, subsidies and credit for agriculture are used in an efficient manner. There are large scale inter regional as well as inter farm variations in factor productivity due to varying influence of different factors in different regions. A number of management factors such as timeliness, transplanting, irrigation and application of right 
Table 3: Efficiency of resources use in peach production

\begin{tabular}{ccccccccc}
\hline Variables & Coefficients & APP & Py & MVP & MIC & R & SE & $\begin{array}{c}\text { Percent adjustment } \\
\text { required }\end{array}$ \\
\hline Fertilizer & 0.53 & 8.62 & 3000.00 & 13641.06 & 8788.49 & $1.55^{* *}$ & 0.35 & 35.57 \\
FYM & 0.11 & 1.32 & 3000.00 & 440.48 & 264.82 & $1.66^{* *}$ & 1.01 & 39.88 \\
Plant protection chemicals & 0.14 & 43.80 & 3000.00 & 18647.22 & 4380.01 & $4.26^{* *}$ & 4.39 & 76.51 \\
Human labour & 0.40 & 1.40 & 3000.00 & 1672.95 & 420.80 & $3.98^{* *}$ & 1.49 & 74.85 \\
\hline
\end{tabular}

**inefficiently utilization of resource.

doses of inputs and input mix play an important role in influencing inter-farm variation in crop productivity (Haque 2006). Given the level of technology and prices of both inputs and outputs, efficiency of resource use can further be ascertained by equating the MVP to the productive MIC of resources. A resource is said to be optimally allocated if there is no significant difference between the MVP and MIC i.e. if the ratio of MVP to MIC $=1$.

From the result of resource-use efficiency estimation shown in Table 3, it has been observed that efficiency ratio of fertilizer, FYM, plant protection and labour statistically significant at 5 per cent level. That means all the inputs are not equal to one and underutilized by the farmers.

Fertilizer is greater than unity which means underutilized and increase its usage would lead to maximization of profit and the similar results were presented by Wongnaa and Ofori in 2012. Since FYM is underutilize hence there is need to enhance its usage for the profit maximization. Reason behind the underutilization for FYM is the presence of less livestock.

The efficiency ratio of plant protection chemicals (4.26) shows that little quantity of plant protection chemicals has been used by the farmers in the study area that has been to say the cost of using plant protection chemicals has been small compared to the marginal value product. This suggests that the farmers can incur more cost in plant protection chemicals so as to be efficient. Since plant protection chemical is underutilize hence there need to increase its usage for the profit maximization. Plant protection chemical has been found to be underutilized by farmers due to lack of technical knowledge. Farmers don't have the knowledge about particular diseases affecting the crop and they don't know appropriate time for chemical treatment.
Amongst the variables under study, that human labour is greater than unity which means underutilized and increased utilization will increase profit. Similar result were obtained Tambo et al. (2010). The reason behind under- utilization of labour is the shifting of family labour from agriculture to service sector.

The fertilizer, FYM, Plant protection chemicals and human labour have been underutilized and require $35.57,39.88,76.51$ and 74.85 per cent addition, respectively of these inputs for optimal production to be achieved as shown in Table 3 and similar results were shown by Karthick et al. in 2013.

Since all the inputs have been included in the study has found to be under-utilized of the production function and fall in zone I.

\section{CONCLUSION}

The resource use efficiency of peach production has been estimated by Cobb-Douglas production function. The study has shown that fertilizer, FYM and labour were significantly affecting the peach production. These resources were underutilized thus there is need for proper utilization of the resources for optimum level of production. Increasing trends in returns to scale of peach steers the planner to plan production strategies for long run so as to safeguard the interests of farmers' involved in production process. The balanced use of these inputs by the orchardists can enhance the peach productivity. For better disposal of peach produce, the producer-industry linkages needs to developed as this crop has potential for processing and preservation. Model of cooperative farming should be developed to ensure better marketing for the harvest of the crop. Adoption of modern farm techniques should be encouraged by creating awareness among the producers. Short 
term training programs should be organized in the peach producing areas regarding the diseases management, high density planting and scientific methods of cultivation in order to enhance the skill of producers to maximize the net profit. Government subsidies can also help reduce the marginal input cost and hence improve efficiency. Peach production is a profitable enterprise in Himachal Pradesh and is in its mature state as depicted by positive and increasing returns to scale.

\section{REFERENCES}

Anonymous. 2016a. National Horticulture Board, New Delhi.

Anonymous. 2016b. Directorate of Economics and Statistics, Himachal Pradesh.

Awasthi, R.P., Bhutani, V.P., Kaith, NS. and Sharma, JC. 1999. Mineral nutrient status of peach orchards in Sirmour district of Himachal Pradesh. Indian journal of Horticulture, 56(3): 194-200.

Chand, H., Guleria, C., Guleria, A. and Kasyap, R. 2017. Resource use efficiency and marketing analysis of apple crop in Shimla district of Himachal Pradesh. International Journal of Farm Sciences, 7(1): 154-159.

Chapke, R.R., Mondal, B. and Mishra, J.S. 2011. Resource-use efficiency of sorghum (Sorghum bicolor) production in rice (Oryza sativa)-fallows in Andhra Pradesh, India. Journal of Human Ecology, 34(2): 87-90.
Ghosh, S.P. 2001. Temperate fruit production in India. Acta Horticulture, pp. 565-132.

Haque, T. 2006. Resource use efficiency in Indian agriculture. Indian Journal of Agricultural Economics, 61(1): 65-76.

Karthick, V., Alagumani, T. and Amarnath, J.S. 2013. Resource use Efficiency and Technical Efficiency of Turmeric Production in Tamil Nadu - A Stochastic Frontier Approach. Agricultural Economics Research Review, 26(1): 109-114.

Mijindadi, N.B. 1980. Production Efficiency on Farms in Northern Nigeria, Ph.D Thesis, submitted to Cornell University, USA.

Nijjar, J.S. and Khajuria, H.N. 1979. New peach cultivars for Punjab. The Punjab Horticultural Journal, 19: 46-49.

Rahman, S.A. and Lawal, A.B. 2003. Economic analysis of maize based cropping systems in Giwa local government area of Kaduna State, ASSET Report Series No. 3, Nigeria.

Tambo, J.A. and Gbemu, T. 2010. Resource-use Efficiency in Tomato Production in the Dangme West District, Ghana. In: Conference on International Research on Food Security, Natural Resource Management and Rural Development, held at Eidgenossische Technische Hochschule, Zurich 14-16 September.

Wongnaa, C.A. and Ofori, D. 2012. Resource-use Efficiency in Cashew Production in Wenchi Municipality, Ghana. Agris on-line Papers in Economics and Informatics, 6(2): 73-80. 